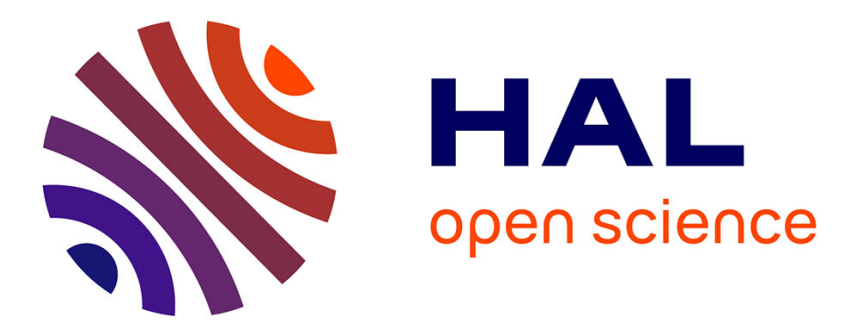

\title{
Design and Material Analysis of Spherical Mobile Robot for Bouncing Mechanism
}

Muhammad Amirul Abdullah, Salmiah Ahmad, Siti Fauziah Toha

\section{To cite this version:}

Muhammad Amirul Abdullah, Salmiah Ahmad, Siti Fauziah Toha. Design and Material Analysis of Spherical Mobile Robot for Bouncing Mechanism. 11th IFIP International Conference on Artificial Intelligence Applications and Innovations (AIAI 2015), Sep 2015, Bayonne, France. pp.282-290, 10.1007/978-3-319-23868-5_20. hal-01385364

\section{HAL Id: hal-01385364 \\ https://hal.inria.fr/hal-01385364}

Submitted on 21 Oct 2016

HAL is a multi-disciplinary open access archive for the deposit and dissemination of scientific research documents, whether they are published or not. The documents may come from teaching and research institutions in France or abroad, or from public or private research centers.
L'archive ouverte pluridisciplinaire HAL, est destinée au dépôt et à la diffusion de documents scientifiques de niveau recherche, publiés ou non, émanant des établissements d'enseignement et de recherche français ou étrangers, des laboratoires publics ou privés. 


\title{
Design \& Material Analysis of Spherical Mobile Robot for Bouncing Mechanism
}

\author{
Muhammad Amirul Abdullah ${ }^{1}$, Salmiah Ahmad ${ }^{1}$, Siti Fauziah Toha ${ }^{1}$ \\ ${ }^{1}$ Department of Mechatronics Engineering, International Islamic University Malaysia, \\ Kuala Lumpur, Malaysia \\ \{salmiah@iium.edu.my\}
}

\begin{abstract}
A spherical mobile robot with a spherical steel spokes shell is introduced in this paper. To have the optimum bouncing capability, the shell configurations should be optimized. The design technique of the optimization is by varying and testing the three main parameters which are the material of the spokes, the number of spokes and diameter for each spoke. The material used in the study are five common commercial material available - 1060 alloy, ASTM A36 steel, cast alloy steel, e-glass fiber and plain carbon steel. The test simulation is run by model in Simulink and SimMechanics. The highest maximum height of bounce indicates the best parameter. It is shown that the ASTM A36 steel with 14 spokes and $4.00 \mathrm{~mm}$ in diameter is the optimum configuration of the spherical mobile robot.
\end{abstract}

Key words: Spherical mobile robot, bouncing, design technique

\section{Introduction}

The mobile robot is widely used in various applications, such as security surveillance, search and rescue, children's education, entertainment and testbed for research. To be safe and adaptive to that kind of environment, the mobile robot area has been evolved in term of design and mechanism. There are many types of design for mobile robot introduced from wheeled, legged and winged. Inspired by Halme in 1996 [1], a spherical mobile robot has come to the mobile robot area which having many advantages compared to the other designs. It can have both rolling and bouncing mechanism in one single body. With one single contact point with the ground, the spherical structure can freely rotate about any axis of rotation and all positions are stable. The shape of the sphere provides complete symmetry and a soft, safe and friendly looking without any sharp corners or protrusions. There are researches on the mechanism of the spherical mobile robot and yet there is lack of research on the material and configuration of the spherical mobile robot. Current research on the spherical mobile robot mechanism can be referred to Roball [2], Omnibola [3], BYQ-III [4], Sphericle [5], SpheRobot [6], and OmniQiu [7]. Each of them is having the different material used and size for the spherical mobile robot. These material and size are not take part as an important aspect for the spherical 
mobile robot as the mechanism is far being concerned. So in this study, five common materials available for industrial and commercial are being simulated to find the best performance for the proposed design of spherical mobile robot with then later studied with the different number and size of spokes of the robot.

\section{Spherical Mobile Robot}

The bouncing spherical mobile robot considered in this study is a mobile robot with a sphere shape closed by metal spokes. The mechanism of the spherical mobile robot is an internal driving unit (IDU) which inside of the metal spokes. These metal spokes are chosen due to it can absorb impacts either during rolling or landing. Moreover, the used of the metal spokes is to replicate the spring to create a jumping motion for the spherical mobile robot. This jumping ability add-up the advantages of the spherical mobile robot to relocate its position easily from point to point.

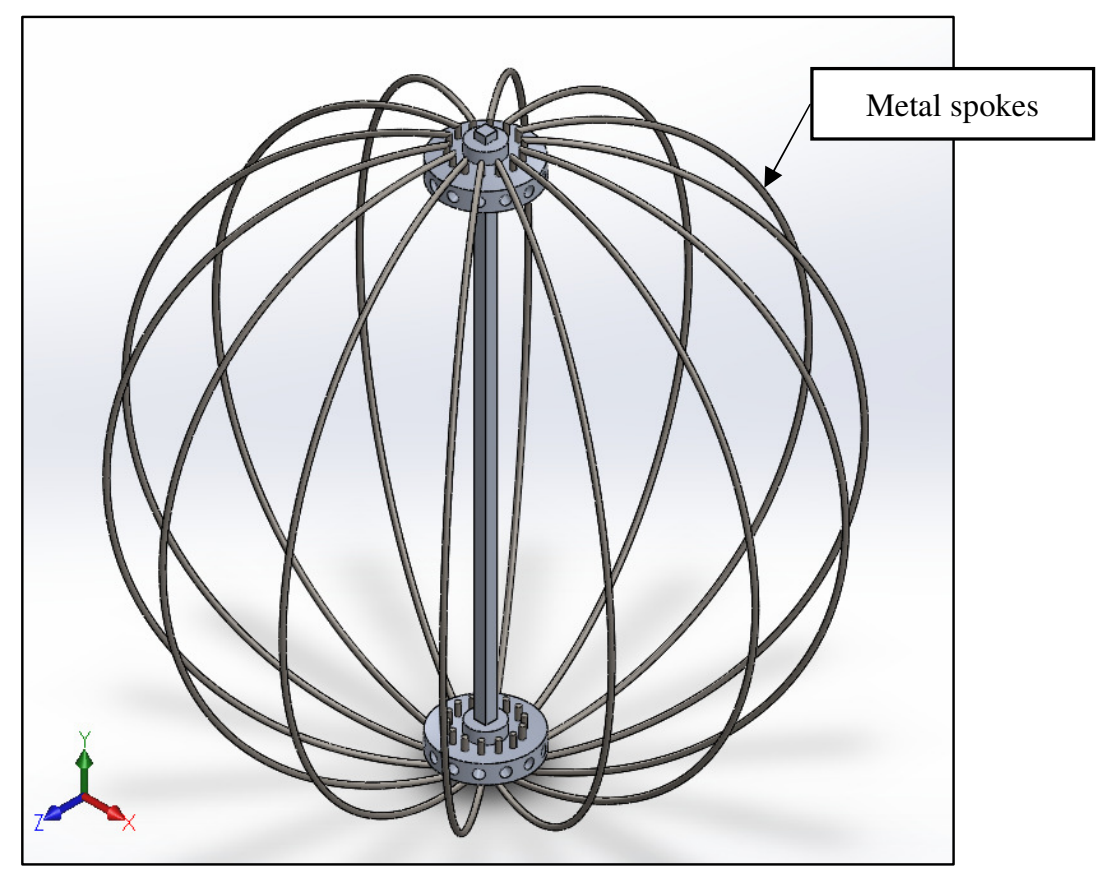

Fig. 1. The proposed design of spherical mobile robot

\subsection{Mathematical Model}

As the metal spokes replicate as a spring, the spherical mobile robot shell design can be modeled as a mass-spring-damper model [8] as in Figure 2. It indicated that 
the spherical mobile robot is subjected to the equation of motion in Equation 1 when the ball is in contact with the ground where $m$ is mass, $x$ is spherical mobile robot position measured from its center of mass, $c$ is viscous damping, $k$ is linear stiffness or spring constant, and $g$ is gravity acceleration.

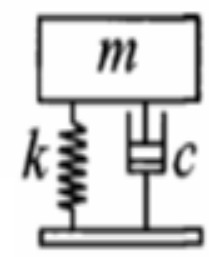

Fig. 2. A mass-spring-damper model of the spherical mobile robot

$m \ddot{x}+c \dot{x}+k x=-m g$

\subsection{Design Scope}

\subsubsection{Spokes Material}

Different materials give different properties of the design. The type of material will influence the design shape, stress, strain, fatigue, impact, wear, creep, and corrosion of the spherical mobile robot. As the study is not to introduce a new type or new composition of material, five common type of materials available are chosen for the study.

1060 Alloy - is a relatively low strength, high purity alloy with a $99.6 \%$ minimum aluminum content. It is noted for its excellent welding characteristics and formability along with good corrosion resistance. It has excellent forming capability by cold or hot working with commercial techniques and may be welded by standard commercial methods.

ASTM A36 Steel - is a typical constructional grade ferritic-pearlitic steel widely used for land vehicles and structures and is easily welded without special heat treatments.

Cast Alloy Steel - is a common type of alloy steel available where it can be customized through casting process to improve its material properties.

E-Glass Fiber - is known in the industry as a general-purpose fiber for its strength and electrical resistance. It is the most commonly used fiber in the fiber reinforced polymer composite industry. 
Plain Carbon Steel - is a basic carbon steel. Its strength depends on its carbon content. Low carbon content makes a soft and easily form steel. Higher the carbon content, harder and stronger the steel.

\subsubsection{Number of Spokes}

A different number of spokes will be represented by different number of spring by the mass-spring-damper model in Figure 2. It should affect the value of stiffness. Even though the spokes can be varied in numbers and diameter, the parameter is limited to the overall outer diameter of the spherical robot. In the proposed design of the spherical mobile robot, its outer diameter is limited to $240 \mathrm{~mm}$ which is a standard size of a basketball ball. This is to ensure the spherical mobile robot can be further study and validated with respect to the basketball ball.

\subsubsection{Diameter of Spokes}

In contrast with the different number of spokes, the different size of the diameter of the spokes indicates the diameter size of the spring in the mass-spring-damper model. Each number of spokes and diameter of spokes should have a different weight of effect in the spherical mobile robot. This different weight of effect can be further shown by the results of the simulation.

\section{Simulation Setup}

The experiment is modeled using MATLAB software which involved Simulink and SimMechanics features. The spherical mobile robot designed using Solidworks is exported to the experiment. Each of the parameters is designed and exported separately. The experiment is run by varying the initial drop height of the spherical mobile robot from $2.4 \mathrm{~m}$ (which is ten times the overall diameter of the robot) to 0.0 $\mathrm{m}$. The first run of the simulation by varying the material of the spokes. From the first run result, the best material is selected and used for the second run. The best material from the first run is re-run with different number of spokes (10 to 14 spokes). Again, the best number spokes obtained from the second run is simulated with different size of spokes diameter $(1.0 \mathrm{~mm}$ to $4.0 \mathrm{~mm})$ in the third run. The best parameter is selected by taking the highest maximum bouncing height. The data are collected and stored for each run. The graph for each comparison is plotted. 


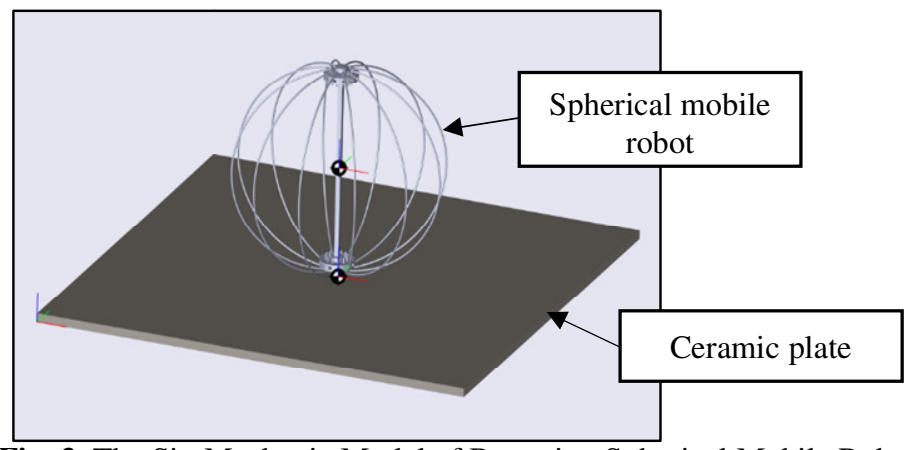

Fig. 3. The SimMechanic Model of Bouncing Spherical Mobile Robot

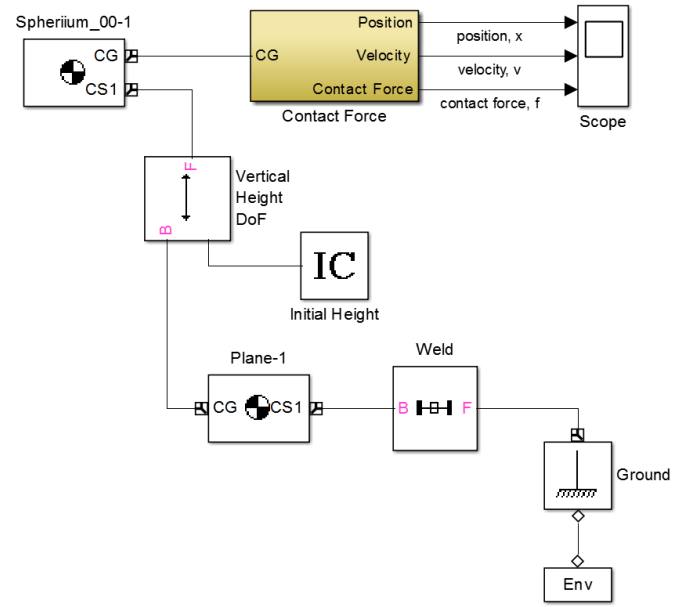

Fig. 4. The Simulink Model of Bouncing Spherical Mobile Robot 


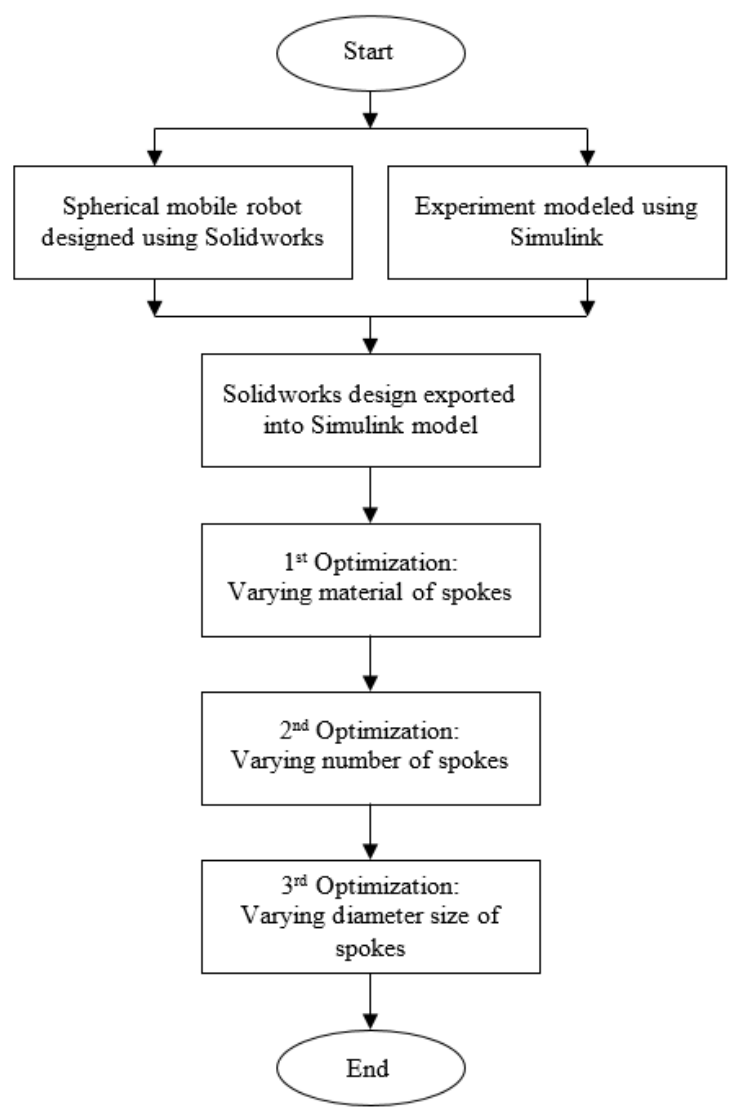

Fig. 5. Flowchart of Optimization for Bouncing Spherical Mobile Robot

\section{$4 \quad$ Results and Discussion}

The collected experimental simulation data are plotted based on the subjected parameter as in Figure 6 to 8.

In Figure 6, the five different type of spokes materials have given two group of material which are ASTM A36 steel, plain carbon steel and cast alloy steel in higher maximum height and the others E-glass fiber and 1060 alloy in the group of lower maximum height. For these three materials in the higher maximum height group, the ASTM A36 steel shows the best performance and proceeded to the next step. 
In Figure 7, it is shown that a different number of spokes are not significant to the maximum bouncing height within the same size of spokes diameter. The maximum different of maximum height between the spokes is $0.0387 \mathrm{~m}$ which is relatively small to take an impact to the spherical mobile robot. Though it gives relatively small affect to the maximum height, the result is considered as the objective of the study is to find the best configuration for the spherical mobile robot shell. The number of spokes of 14 is chosen.

As mentioned in 2.2.3, the diameter of the spokes shows a high weightage of effect on the spherical mobile robot maximum height. The different results of each diameter sizes prove that the diameter of spring in the mass-spring-damper model really make a role in the part of design any mass-spring-damper related robot. By result in Figure 8, spokes diameter of $4.0 \mathrm{~mm}$ size is selected as the final size for the spherical mobile robot.

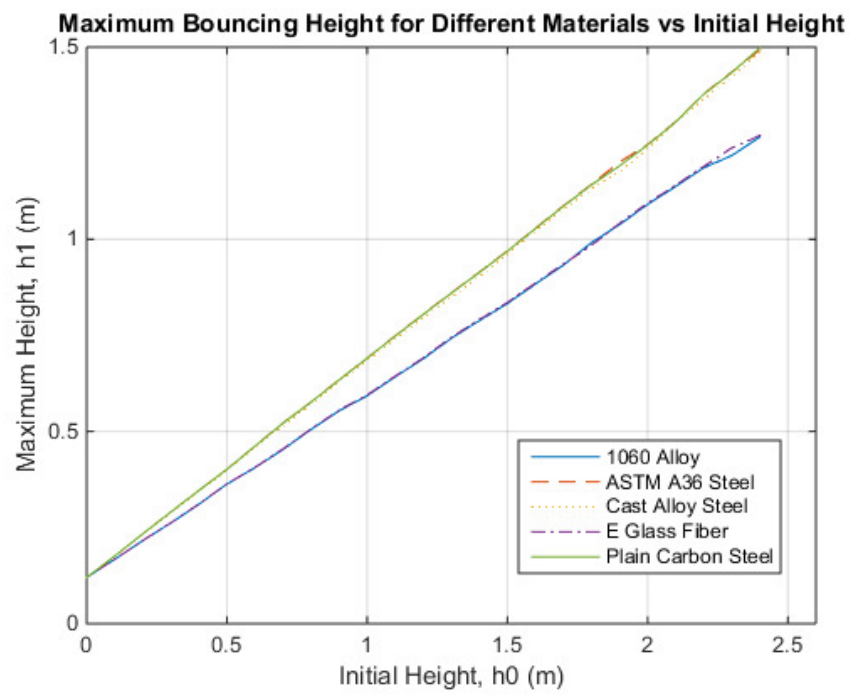

Fig. 6. Maximum bouncing height for the different material of spokes versus initial height. 


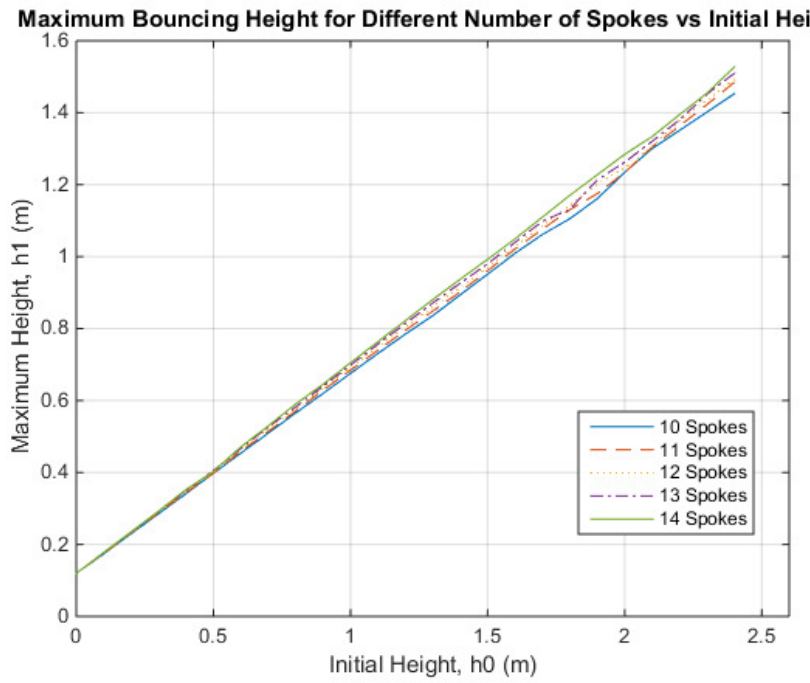

Fig. 7. Maximum bouncing height for a different number of spokes versus initial height.

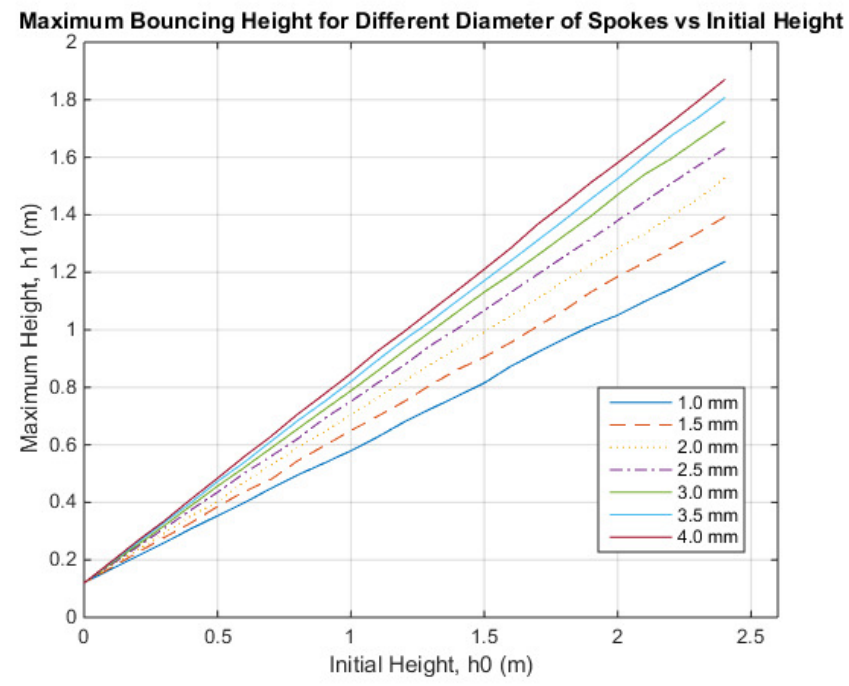

Fig. 8. Maximum bouncing height for the different diameter size of spokes versus initial height. 


\section{Conclusion}

An optimized design for a spherical mobile robot has successfully achieved. The final result of the optimized design is shown in Figure 8 with the red plot of $4.0 \mathrm{~mm}$. The optimized design will be fabricated into prototyped and will be validated. The study also showed that the number of spokes has less impact towards the maximum height compared to the other two parameters which are material and diameter of the spokes. The new prototype will be designed based on the optimized value as in Table 2.

Table 2. Optimized Parameter

\begin{tabular}{ll}
\hline Parameter & Value \\
\hline Material & ASTM A36 Steel \\
Number of Spokes & 14 \\
Diameter of Spokes & $4.0 \mathrm{~mm}$ \\
\hline
\end{tabular}

Acknowledgments. Authors would like to express their gratitude to International Islamic University Malaysia for providing facilities to conduct this research. This research was funded by Ministry of Education under Fundamental Research Grant Scheme (FRGS).

\section{References}

[1] A. Halme, T. Schonberg, and Y. Wang, "Motion control of a spherical mobile robot," in Advanced Motion Control, 1996. AMC'96-MIE. Proceedings., 1996 4th International Workshop on, 1996, vol. 1, pp. 259-264.

[2] F. Michaud and S. Caron, "Roball, the rolling robot," Auton. Robots, vol. 12, no. 2, pp. 211-222, 2002.

[3] M. Jaimez, J. J. Castillo, F. García, and J. a. Cabrera, "Design and Modelling of Omnibola (C), A Spherical Mobile Robot,” Mech. Based Des. Struct. Mach., vol. 40, no. 4, pp. 383399, Oct. 2012.

[4] D. Liu, H. Sun, Q. Jia, and L. Wang, "Motion control of a spherical mobile robot by feedback linearization," in Intelligent Control and Automation, 2008. WCICA 2008. 7th World Congress on, 2008, pp. 965-970.

[5] A. Bicchi, A. Balluchi, D. Prattichizzo, and A. Gorelli, "Introducing the 'SPHERICLE': an experimental testbed for research and teaching in nonholonomic," in Proceedings., 1997 IEEE International Conference on Robotics and Automation, 1997, vol. 3, pp. 2620 2625.

[6] D. Pokhrel, N. R. Luitel, S. Das, and D. N. Ray, "Design and Development of a Spherical Robot (SpheRobot)," in Proceedings of the 1st International and 16th National Conference on Machines and Mechanisms (iNaCoMM2013), IIT Roorkee, India, 2013, pp. 735-741.

[7] W.-H. Chen, C.-P. Chen, W.-S. Yu, C.-H. Lin, and P.-C. Lin, "Design and implementation of an omnidirectional spherical robot Omnicron," 2012 IEEE/ASME Int. Conf. Adv. Intell. Mechatronics, pp. 719-724, Jul. 2012.

[8] M. Nagurka and S. Huang, "A mass-spring-damper model of a bouncing ball," in Proceedings of 2004 American Control Conference, 2004, vol. 1, pp. 499-504. 